\title{
Exploitation of Sentinel-2 images for long-term vegetation monitoring at a former ore processing site
}

\author{
S. Fabre ${ }^{1}$, A. Elger ${ }^{2}$, T. Riviere ${ }^{1}$ \\ ${ }^{1}$ ONERA DOTA BP74025 2 av. Edouard Belin, FR-31055 TOULOUSE CEDEX 4 sophie.fabre@onera.fr \\ ${ }^{2}$ EcoLab, Université de Toulouse, CNRS, INPT, UPS, Toulouse; arnaud.elger@univ-tlse3.fr
}

KEY WORDS: Vegetation survey, Change detection, Mining site, Phytostabilization, Heavy metal, Multispectral, Multitemporal, Sentinel-2 satellite

\begin{abstract}
Excess metals in the soil or in plant tissues tend to have negative effects on plant health, growth, and biomass accumulation. The search for stressed or unusual growth patterns in cover vegetation has been enhanced by the use of vegetation index in the context of excessive exposure to heavy metals in the soil. This study aims to improve the monitoring of phyto-stabilized and natural vegetation of an ore processing site for several years after its closure by using multiple Sentinel-2 images. The time series is made up of 13 images, one image per season for four years. NDVI (Normalized Difference Vegetation Index), the most widely known and used vegetation index in the scientific literature, is used in combination with other spectral indexes identifying built-up areas and bare soils in order to enhance vegetation. A change detection technique based on absolute difference of vegetation maps is applied to detect abrupt changes related to meteorological conditions and significant environmental changes.
\end{abstract}

\section{CONTEXT, OBJECTIVE}

Mining activities are an important source of soil heavy metal pollution. Vegetation mapping and monitoring near mine sites following the end of operations could allow one to provide information on the results of rehabilitation or to detect and control residual contaminants through the vegetation health (Davids, 2018). Vegetation is then considered as an indicator of soil pollution detected by means of optical imaging, the changes in the biochemical characteristics of vegetation (pigment content, cell structure, water content, physiological state ...) having an impact on its optical properties (Slonecker, 2018) (Gholizadeh, 2019) (Lassalle, 2019).

Different papers have reviewed the effects of Heavy Metals (HM) on vegetation reflectance (Slonecker, 2018) (Ong, 2019). The vegetation sensitivity to HM depends on the soil contamination level, the species, the phase of growth cycle and the environment. The increase of HM in the soil tends to reduce photosynthetic activity, concentration in chlorophyll and vegetation growth (Slonecker, 2018).

Vegetation spectral indices, related to biophysical or biochemical parameters (such as leaf pigments, water content, vegetation fraction cover...), are considered as indicators of the state of the health of a plant or can be used to assess vegetation cover in the context of soil contamination (Zhang, 2018). The Normalized Difference Vegetation Index (NDVI) (Rouse, 1973) is often used to characterize canopy growth or vigour and related to LAI (Leaf Area Index) (Xue, 2017). This index, based on the absorption of light by vegetation in the red band and its reflectance in the NIR (Near InfraRed) band, is especially suitable for monitoring low to moderate density vegetation. Some others indexes, such as PRI (Photochemical Reflectance Index), RVI (Ratio Vegetation Index), HMSSI (Heavy Metal Stress Sensitive Index) or $\mathrm{CI}_{\text {red-edge, }}$ have been used to detect vegetation stress related to heavy metals (Slonecker, 2018) (Zhang, 2018). The choice of the most appropriate spectral index or of a combination of spectral indices depends on the study (study site, objective).

Vegetation phenology derived from high temporal resolution satellite data has received increasing attention for applications in environmental monitoring. To do this, time series of vegetation index data can be obtained from satellite Sentinel-2 images, with spatial resolution of 10 and $20 \mathrm{~m}$ according to the spectral domains and high temporal coverage (five days revisit time) (Frampton, 2013).

The objective of this study is to survey vegetation cover changes many years after the closure and the revegetation of an ore processing site by using Sentinel-2 time series. Time series are then used to monitor changes in vegetation at the habitat scale throughout several years. The high temporal repeatability ensures both an analysis of the inter-annual variability of habitat change over a large temporal period and an analysis of habitat phenology throughout one year. Some areas of the site have been phyto-stabilized while in other areas, natural vegetation has developed over the years. The phyto-stabilization involves the reduction of the mobility of metal or metalloid in contaminated soil by the introduction of plants in combination with the use of metal immobilizing soil amendments to reduce the negative environmental impact.

\section{DATA SET}

\subsection{Study site}

The study area is a former ore processing site in France closed in 2004 and managed by an operator of the French State. The site covers approximately 120 hectares. Six study zones have been localised by the site manager (Figure 2). In 2006, three of these zones were phyto-stabilized and the other areas correspond to natural vegetation.

\subsection{Satellite images}

The Sentinel-2 images available on the study site were selected according to their quality (cloud-free, level 2A i.e. georeferenced reflectance images available on the Theia platform) between 2016 and 2019 (Theia). One image per season is selected until February 2019. For each image, the spectral bands are resampling to the spatial resolution of $10 \mathrm{~m}$. 
No image could be used in winter 2016 due to the presence of clouds. The time series is made up of 13 images (Table 1).

\begin{tabular}{|l|c|c|}
\hline Year & \multicolumn{2}{|c|}{ Acquisition date } \\
\hline \multirow{4}{*}{2016} & Month & Day \\
& May & 21 \\
& August & 26 \\
& October & 15 \\
& February & 25 \\
2018 & May & 16 \\
& August & 21 \\
& October & 13 \\
2019 & February & 27 \\
& May & 11 \\
& August & 19 \\
& October & 25 \\
& February & 22 \\
& May & 13 \\
\hline
\end{tabular}

Table 1. S-2 time series description

\section{PROCESSING CHAIN}

A processing chain with three modules has been set up ( Figure 1). These modules are: a spectral index database to provide index maps representing built-up areas, bare soils and vegetation, a map combination module in order to provide the vegetation cover maps and a change detection module to compare vegetation cover maps and localize changes. The processing chain's inputs are spectral reflectance images and it produces change detection maps.

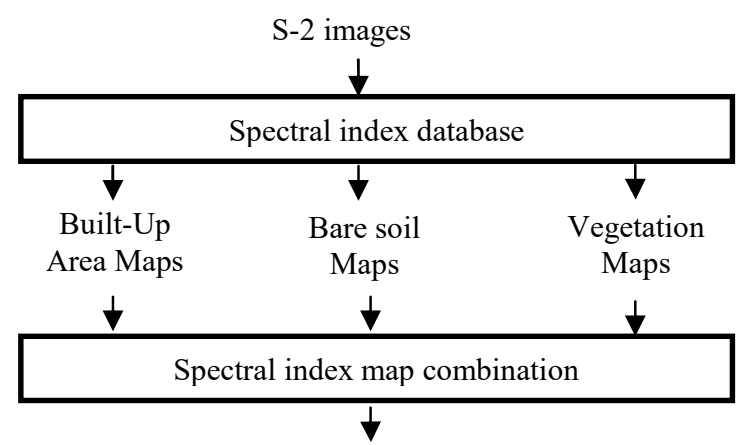

Temporal series of vegetation cover map $\downarrow$

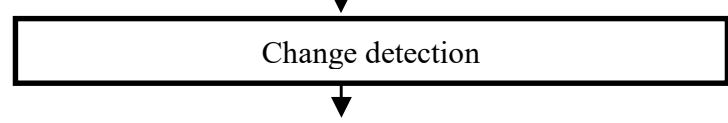

Change detection maps

Figure 1. Processing chain

Our spectral database is applied on each satellite image to highlight vegetation pixel and mask pixels representing other land cover classes like bare soils, built-up area, water .... NBAI (Normalized Built-up Area Index) and BRBA (Band Ratio for Built-up Area), previously used to identify roads or buildings in S-2 images, are applied (Valdiviezo, 2018). NDWI (Normalized Difference Water Index) and mNDWI (modified Normalized Difference Water Index) are retained to highlight water areas in S-2 images (Du, 2016). SAVI (Soil Adjusted Vegetation Index) and DBSI (Dry Bareness Spectral Index) are applied to identify bare soil pixels (Rasul, 2018). These indexes are combined with NDVI to provide vegetation cover map associated for each S-2 image (Figure 2). The combination of vegetation index with indexes related to other land cover classes allows a reduction of false alarms.

The change detection method is based on the absolute difference, applied pixel by pixel, between two vegetation cover maps associated to two different dates (Hussain, 2013). The vegetation cover maps are then compared over different time periods to assess ecologically significant changes.

\section{RESULTS}

A visual analysis of the vegetation cover maps is conducted in order to monitor the evolution of the vegetation cover over the seasons and the years (Figure 2, Figure 3).

For each year, there are two seasons with the most significant vegetation cover (Figure 2). The appropriate seasons for the annual vegetation monitoring in this context are then winter and spring. Zones 1 and 5 have permanent bare soil pixels with no vegetation cover regardless of the year and the season (Figure 2, Figure 3). Some in-situ data acquired in zone 5 are measured in an attempt to explain the total absence of vegetation. Two bare soil areas in zone 5 correspond to a marked metal signature and the third area in zone 5 is characterized by a very marked metal signature.

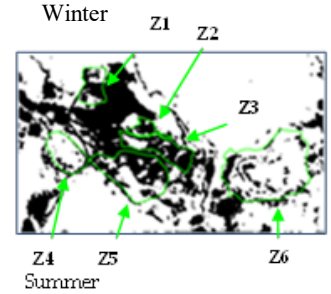

Spring
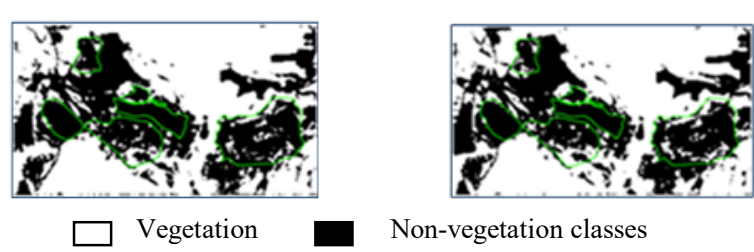

Non-vegetation classes

Figure 2. Temporal evolution of the vegetation cover map by season in 2017. Zones 1, 2 and 5 (named Z1, Z2, Z5) are phytostabilized. Zones 3, 4 and 6 (named Z3, Z4, Z6) are covered by natural vegetation.

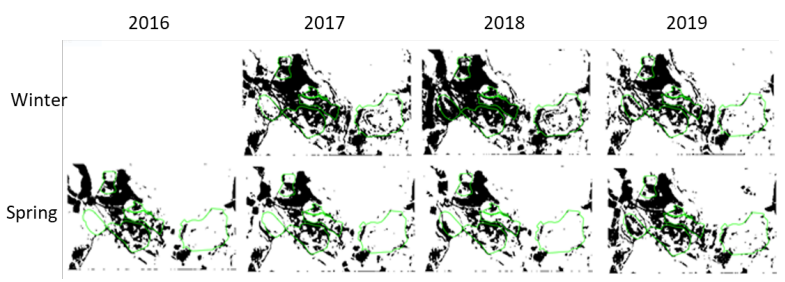

Figure 3. Annual evolution of the vegetation cover map in winter and spring.

Bare soil spectral reflectances are measured in-situ with an ASD (Analytical Spectral Devices) Fieldspec-Pro spectroradiometer in the $(400-2500 \mathrm{~nm})$ spectral domain with a spectral resolution of $3 \mathrm{~nm}$ in the (400-1000 nm) domain and of 10-12 $\mathrm{nm}$ in the $(1000-2500 \mathrm{~nm})$ domain. A Spectralon panel was used as white reference. Figure 4 represents the spectral signatures of bare soil areas with a marked metal signature. In the visible spectral domain, the spectral signature is not particularly convex with a high level corresponding to soils 
with a large amount of lime and a small quantity of iron oxide (Escadafal, 1988) (Lesaignoux, 2013). The absorption band at $2330 \mathrm{~nm}$ is related to carbonate. Soils seem to be directed towards limestone soils which are poor in organic matter. Further in-situ investigations (spectral signature measurements of bare soil area with very marked metal signature, soil texture analysis...) have to be conducted in order to define whether or not the lack of vegetation is related to contamination level and/or soil texture.

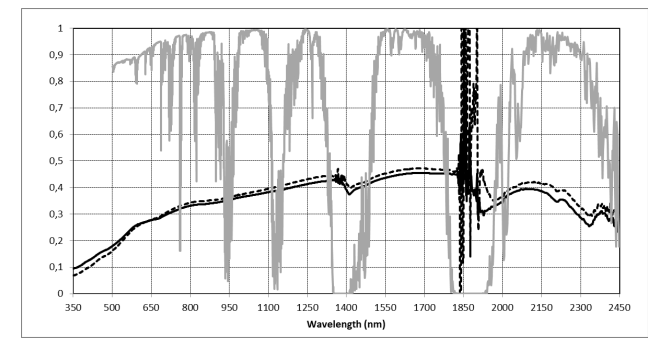

Figure 4. Bare soil spectral signatures measured in-situ for the two areas with marked metal signature (in black). Atmospheric transmission (in grey): spectral bands related to low transmission cannot be processed.

The percentage of vegetation pixel by zone is computed (Figure 5). The same vegetation phenology, reduction of vegetation cover in summer and growth in spring, is observed for phytostabilized and natural vegetation zones. The phyto-stabilized zones and zone 6 with natural vegetation maintain a greater vegetation cover in summer and autumn compared to zones 3 and 4 . This can be explained by the difference in vegetation species and the presence of pines.

Globally, the vegetation cover increases significantly between summer 2016 and summer 2018. Abrupt changes are observed in autumn 2018 (Figure 5).

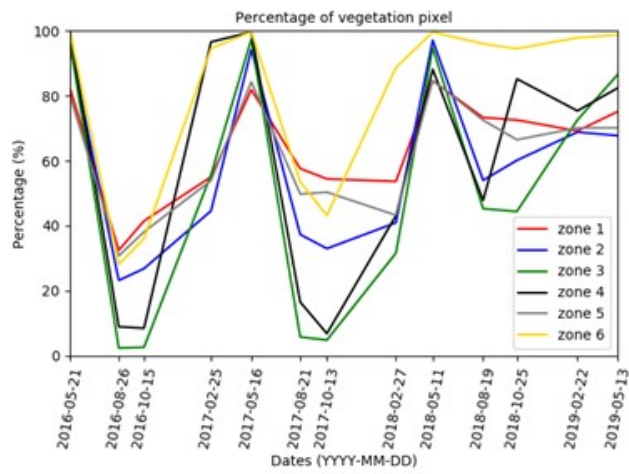

Figure 5. Temporal evolution of the percentage of vegetation cover pixel by zone between 2016 and 2019 .

The results obtained are linked to the meteorological conditions (rainfall, temperature) (Figure 6, Figure 7). The vegetation cover changes after winter 2019 are explained by the heavy rainfalls in the autumn of 2018. February 2018 is the coldest month and the increase in the number of vegetation pixels between the autumn and the winter of 2018 is smaller than the increase observed in 2017.

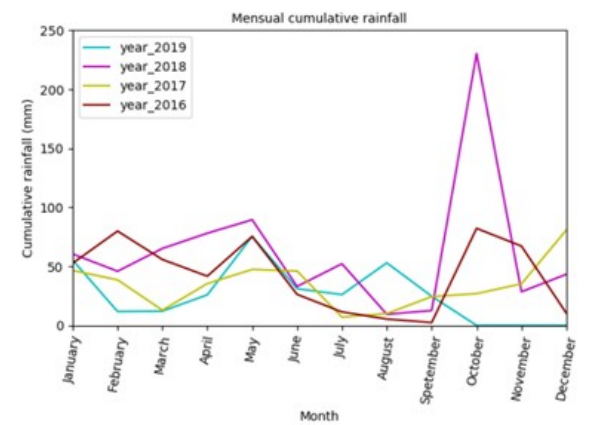

Figure 6. Monthly cumulative rainfall per year between 2016 and 2019 (in mm). Very high rainfalls in autumn 2018. The data are not available after October 2019.

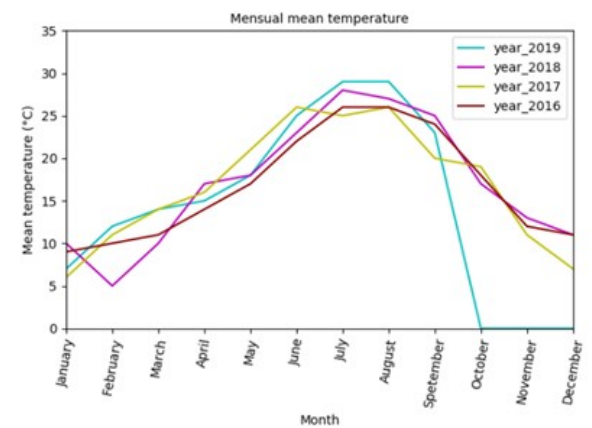

Figure 7. Temporal evolution of the average monthly temperature (in ${ }^{\circ} \mathrm{C}$ ). Lowest temperature in winter 2018. The data are not available after October 2019.

The change detection method is applied on the vegetation cover maps and spatial localization of changes is provided (Figure 8). Globally, many pixels do not change over the years. Between the spring of 2016 and the spring of 2018, on average per area, $96 \%$ of the pixels are unchanged. For most of the pixels undergoing changes, there is an increase of vegetation cover except for in zone 4 . This is particularly noticeable for phytostabilized areas. Between 2016 and 2018, part of zone 4, representing $7 \%$ of its pixel, has a well-localized decrease of vegetation. Between the spring of 2016 and the spring of 2019 , for all zones except zone 6 , pixels with decreasing vegetation cover are randomly spatially distributed (Figure 8, Table 2). There is no apparent difference between phyto-stabilized and natural vegetation areas. In order to explain the spatial distribution of this vegetation cover decrease, spatial information should be exploited for example through airborne hyperspectral imagery. The difference in behavior for zone 6 can be explained by the presence of well-developed trees, mainly pines and poplars. 

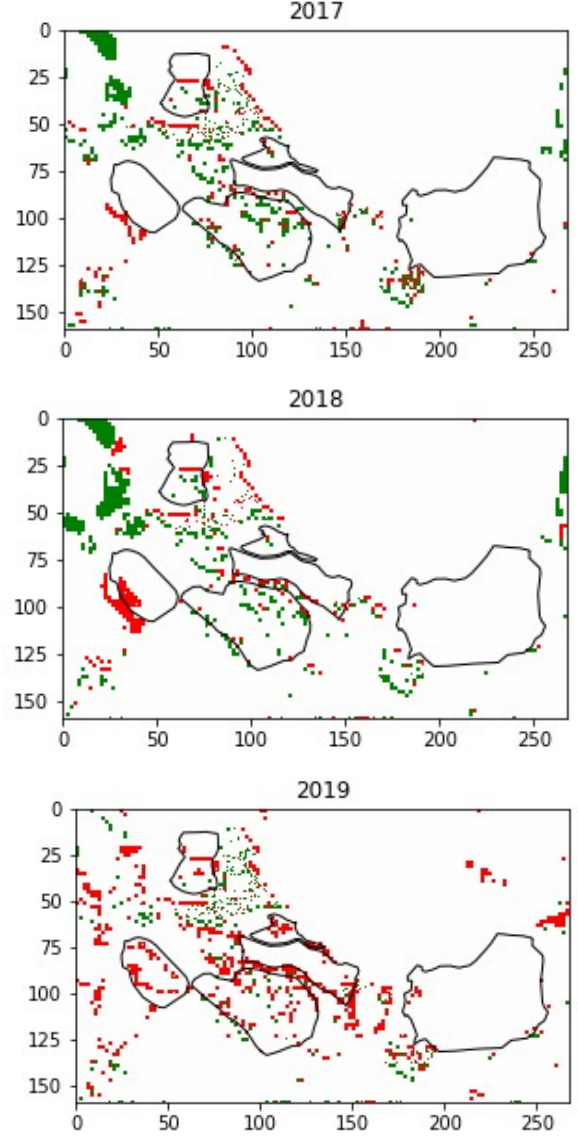

No change

Vegetation cover reduction

Vegetation cover increase

Figure 8. Change detection maps in spring. The reference year is 2016. Cover vegetation maps of years 2017, 2018 and 2019 are compared to 2016.

\begin{tabular}{|l|c|c|}
\hline Zones & \multicolumn{2}{|c|}{$\begin{array}{c}\text { Percentage of vegetation } \\
\text { cover pixels (\%) }\end{array}$} \\
\hline & Increase & Decrease \\
Z1 & 1 & 6 \\
Z2 & 0 & 9.4 \\
Z3 & 0.3 & 4 \\
Z4 & 0 & 10 \\
Z5 & 1.5 & 7.3 \\
Z6 & 0 & 0.7 \\
\hline
\end{tabular}

Table 2. Variation of the percentage of vegetation cover pixels between the spring of 2016 and the spring of 2019 by zone

In order to illustrate the abrupt change in the vegetation cycle observed in the autumn of 2018 and related to heavy rainfall episode mentioned above (Figure 5, Figure 6), the map detection change of vegetation cover is calculated between the autumn of 2016 and the autumn of 2018 (Figure 9). Phytostabilized zones (Z1, Z3 and Z5) and zone 3 have between 11 and $22 \%$ of pixels with increasing vegetation cover. Zones 4 and 6 have between 40 and $45 \%$ of pixels with increasing vegetation cover.
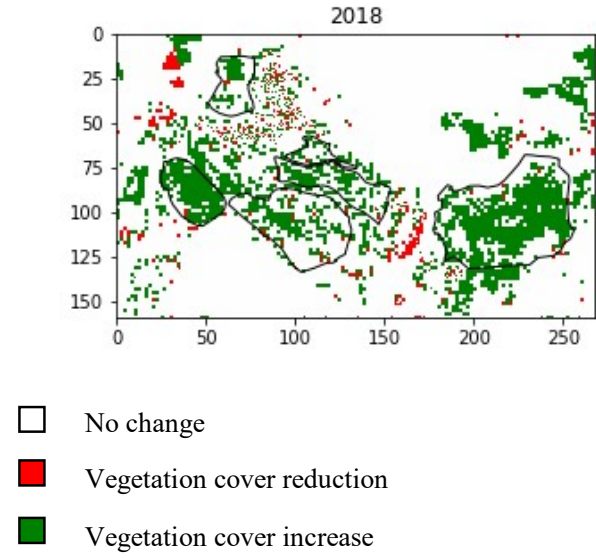

Figure 9. Change detection map between the autumn of 2016 and the autumn of 2018. The reference year is 2016 .

Even if it is difficult to identify specific behaviour according to vegetation type (natural or phyto-stabilized vegetation), the change detection tool proposed, based on monitoring vegetation cover evolution over seasons and years, allows fast and relevant analysis of abrupt and global changes.

\section{CONCLUSIONS}

The Sentinel-2 time series allow the monitoring of vegetation cover after the closure of the mine. Overall and abrupt changes of the vegetation cycle linked to meteorological conditions are highlighted. Specific changes have also been identified: the identification of a permanent bare soil area without vegetation cover whatever the year and season since 2016, changes identification of the most disturbed area, difference in the vegetation cycle according to area a priori related to the presence of different species. In the near future, spatial information will be exploited by the investigation of geostatistics (variogram calculation, kriging interpolation...) for the analysis and estimation of spatial correlation (which can also be applied to the analysis of temporal correlation). Moreover, vegetation spectral indexes will be investigated in order to assess vegetation traits related to biophysical or biochemical parameters

\section{ACKNOWLEDGEMENTS}

This work was performed within the framework of the APR COMPOST project between ONERA and Ecolab, funded by the CNES. The authors gratefully acknowledge the BRGM.

\section{REFERENCES}

Davids, C., Rouyet, L.R emote sensing for the mining industry. 2018, Report, Project RESEM, Northern Research Institute (Norway), ISBN: 978-82-7492-417-8, ISSN: 2535-3004.

Du, Y., Zhang, Y., Ling, F., Wang, Q., Li, W., Li, X. Water Bodies' Mapping from Sentinel-2 Imagery with Modified Normalized Difference Water Index at 10-m Spatial Resolution Produced by Sharpening the SWIR Band, 2016, Remote Sensing, 8, 354; doi:10.3390/rs8040354

Escadafal, R., Girard, M.C., Courault, D., Modeling the relationships between Munsell soil color and soil spectral properties, 1988, Remote Sensing is a Tool for Scientists, 5., Budapest (HUN), 1988/04/11-15. 
Frampton, W.J., Dash, J., Watmough, G., Milton, E.J. Evaluating the capabilities of Sentinel-2 for quantification estimation of biophysical variables in vegetation, 2013, ISPRS Journal of Photogrammetry and Remote Sensing, 82, 83-92.

Gholizadeh, A., Kopačková, V., Detecting vegetation stress as a soil contamination proxy: a review of optical proximal and remote sensing techniques, 2019, International Journal of Environmental Science and Technology.

Hussain, M., Chen, D., Cheng, A., Wei, H., Stanley, D., Change detection from remotely sensed images: From pixel-based to object-based approaches, 2013, ISPRS Journal of Photogrammetry and Remote Sensing, 80, 91-106.

Lassalle, G., Fabre, S., Credoz, A., Hédacq, R., Borderies, P., Bertoni, G., Erudel, T., Buffan-Dubaud, E., Dubucq, D., Elger, A. Detection and discrimination of various oil mixtures in soils using vegetation indices: A multi-scale approach. March 2019, Science of the Total Environment, vol. 655, 113-1124.

Lesaignoux A., Fabre, S., Briottet, X., Influence of soil moisture content on spectral reflectance of bare soils in the 0.4 $14 \mu \mathrm{m}$ domain, 2013, International Journal of Remote Sensing, $34: 7,2268-2285$.

Ong, C., Carrère, V., Chabrillat, S., Clark, R., Hoefen, T., Kokaly, R., Marion, R., Souza Filho, C.R., Swayze, G., Thompson, D.R. Imaging Spectroscopy for the Detection, Assessment and Monitoring of Natural and Anthropogenic Hazards, 2019, Surveys in Geophysics, 40, 431-470.

Rasul, A., Balzter, H., Faqe Ibrahim, G. R., Hameed, H.M., Wheeler, J., Adamu, B., Ibrahim, S. Najmaddin, P.M. Applying Built-Up and Bare-Soil Indices from Landsat 8 to Cities in Dry Climates, 2018, Land, 7, 81, doi:10.3390/land7030081.

Rouse, J.W., Haas, R.H., Shell, J.A., Deering, D.W., Monitoring vegetation systems in the Great Plains with ERTS, 10-14 December 1973, In: Third Earth Resources Technology Satellite-1 Symposium, vol. 1,. NASA Scientific and Technical Information Office, Washington, DC.

Slonecker, T. , Fisher, G.B., Aiello, D.P., Haack, B. Visible and infrared remote imaging of hazardous waste: a review, 2010, Remote Sensing, 2, 2474-2508, doi:10.3390/rs2112474.

Theia Data and Services center for continental surfaces. . Available online: https://www.theia-land.fr/pole-theia-2/ (accessed on 20 January 2020).

Valdiviezo-N, J.C., Téllez-Quiñones, A., Salazar-Garibay, A., López-Caloca, A.A. Built-up index methods and their applications for urban extraction from Sentinel 2A satellite data: discussion, 2018, Journal of the Optical Society of America A, 35, 1, 35-44, https://doi.org/10.1364/JOSAA.35.000035.

Xue, J., Su B., Significant Remote Sensing Vegetation Indices: A Review of Developments and Applications, 2017, Journal of Sensors, vol. 2017.

Zhang, Z., Liu, M., Liu X., Zhou, G. A New Vegetation Index Based on Multitemporal Sentinel-2 Images for Discriminating Heavy Metal Stress Levels in Rice, 2018, Sensors, 18, 2172, doi:10.3390/s18072172. 